An initiative offering free pneumococcal vaccination to victims of the Great East Japan earthquake

The Pacific coastline of eastern Japan was severely affected by the massive tsunami that struck on 11 March 2011. The article by Daito et al, ${ }^{1}$ published in Thorax reported a marked increase in the incidence of pneumonia during the disaster. 
I carried out surveys and relief activities in the city of Kesennuma, Miyagi Prefecture, from the sixth day after the earthquake as a member of the first advance party of the Primary Care for All Team (PCAT) dispatched by the Japan Primary Care Association Earthquake Relief Project. Given the conditions in the evacuation centres, the incidence of pneumonia among elderly people was expected to increase. Pneumonia was reported as the most common cause of death among victims of the Great Hanshin-Awaji earthquake in 1995. We therefore consulted Dr Hitoshi Otomo, Chairman of the Kesennuma City Medical Association and a member of the Kesennuma City Disaster Control Headquarters, and formulated a plan to provide pneumococcal vaccination for elderly people in evacuation centres.

The pneumococcal vaccination rate in Japan is only $11 \%$ for people aged over 65 (estimated from the cumulative number of vaccines administered from 1988 to 2010), as opposed to $61 \%$ that was reported in a patient survey conducted by the USA Centers for Disease Control (CDC) in 2010. The number of disaster victims aged over 65 in evacuation centres in Kesennuma as of the end of March was estimated at 6000, and we therefore arranged for 5500 vaccinations. Supplies of 23-valent pneumococcal vaccine were provided by pharmaceutical companies, and syringes and other equipment required for vaccination were purchased and distributed using donated funds of Juntendo University. Vaccination was carried out by members of the PCAT and local medical associations at 82 locations from 13 May to 30 September (82 days). Eventually, 5325 individuals were vaccinated.

The CDC recommends that victims of major disasters should receive pneumococcal polysaccharide vaccine (PPSV23) for adults 65 years of age or older and those 19 through 64 years of age with a chronic immunocompetent medical condition. ${ }^{2}$ After the Great East Japan earthquake, at many instances, victims were preferably treated with therapeutic agents such as antibiotics and analgesics, and vaccination was postponed. Vaccine storage and maintenance require refrigeration and syringes, which may pose difficulties during a disaster. In this initiative, we were only able to offer free vaccination in evacuation centres in a limited number of areas; it may be necessary to develop a framework to enable rapid implementation in all areas after future disasters.

\section{Toshio Naito}

Correspondence to Dr Toshio Naito, Department of General Medicine, Juntendo University School of
Medicine, Hongo2-1-1, Tokyo 113-8421, Japan; naito@juntendo.ac.jp

Competing interests None.

Provenance and peer review Not commissioned; internally peer reviewed.

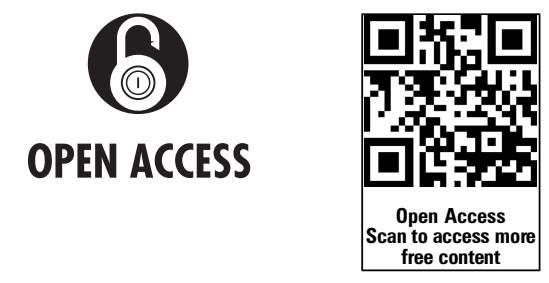

Open Access This is an Open Access article distributed in accordance with the Creative Commons Attribution Non Commercial (CC BY-NC 3.0) license, which permits others to distribute, remix, adapt, build upon this work non-commercially, and license their derivative works on different terms, provided the original work is properly cited and the use is non-commercial. See: http:// creativecommons.org/licenses/by-nc/3.0/

To cite Naito T. Thorax 2013;68:1068-1069.

Received 26 March 2013

Revised 17 April 2013

Accepted 25 April 2013

Published Online First 5 June 2013

Thorax 2013;68:1068-1069.

doi:10.1136/thoraxjn-2013-203633

\section{REFERENCES}

1 Daito H, Suzuki M, Shiihara J, et al. Impact of the Tohoku earthquake and tsunami on pneumonia hospitalisations and mortality among adults in northern Miyagi, Japan: a multicentre observational study. Thorax 2013;68:544-50.

2 Interim Immunization Recommendations for Individuals Displaced by a Disaster. http://emergency.cdc.gov/ disasters/disease/vaccrecdisplaced.asp (accessed 26 Mar 2013). 